\title{
EL PALMERAL DE ELCHE: PATRIMONIO, GESTIÓN Y TURISMO
}

\author{
José Antonio Larrosa Rocamora \\ Departamento de Geografía Humana \\ Universidad de Alicante
}

\section{RESUMEN}

El palmeral histórico de Elche es un sistema agrícola de origen árabe estructurado en parcelas rectangulares, en cuyos límites están plantadas las palmeras. El indudable valor patrimonial de este espacio, protegido legalmente desde 1933, ha sido reafirmado y aumentado en la década de 1990 gracias a la ampliación del concepto de patrimonio hacia los bienes de la tradición popular: fiestas, actividades, técnicas, etc. En este contexto, la UNESCO declaró el palmeral histórico de Elche como Patrimonio de la Humanidad en el año 2000, y con ello se han abierto las puertas del desarrollo del turismo en la ciudad. Sin embargo, la gestión de este espacio no ha sido ni es la más adecuada, en parte debido a la falsa imagen que ha trascendido del palmeral como jardín exótico, imagen que ha sido reproducida en muchos huertos abiertos al público en general y a la actividad turística en particular. La aparición en los últimos años de nuevas tendencias motivacionales en la demanda turística, entre las cuales se halla el aumento de la valoración y la búsqueda de todo lo relacionado con la cultura, abre nuevas posibilidades al desarrollo de un turismo que ayude a proteger y a conservar el palmeral con su impronta agrícola intacta.

Palabras clave: Palmeral de Elche, patrimonio, gestión, turismo, Patrimonio de la Humanidad.

\section{SUMMARY}

Elche's historic Palm Tree Park is an agricultural system of Arabic origin which is laid out in rectangles and whose boundaries are lined with palm trees. The unquestionable patrimonial value of this site, that has been officially protected since 1933, was reaffirmed and increased in the 1990's thanks to the widening of the concept of «heritage» so that it encompassed popular traditions such as festivals, activities and crafts.

* Esta investigación se ha desarrollado dentro de la Acción Integrada «Políticas y mutaciones urbanas y periurbanas: Estudios comparativos en Francia y España mediterráneas», entre el Instituto de Geografía —UMR TELEMME - de la Universidad de Provenza y el Departamento de Geografía Humana de la Universidad de Alicante. 
Within this context, UNESCO declared the historic Palm Tree Park as Heritage of Humanity in the year 2000, which has helped to open the way for tourism in the city. However, up until now, this site has not been managed in the best possible way. This is partly due to the fact that the park has been misconstrued as an exotic garden; an image that has been mimicked by many gardens that are open to the public in general and to tourists in particular. During the last few years, tourist demand has developed new motivational trends, which, amongst other things, reveal an increase in the value given to and interest shown in anything related to culture. The appearance of these new trends opens up new possibilities for the development of tourism that will aid the protection and conservation of the Palm Tree Park, with its hallmark agriculture still intact. manity

Key words: Elche Palm Tree Park, heritage, management, tourism, Heritage of Hu-

\section{Introducción}

Estudios realizados recientemente defienden el origen autóctono de la palmera datilera (PICÓ, 1997), en contra de la suposición general de que fueron los fenicios los que introdujeron este árbol en el sur de Europa. Tanto si esta hipótesis es acertada como si no, de lo que no cabe duda es de que la organización del cultivo es de origen árabe, aunque la red de acequias principales que hizo viable la existencia del palmeral que bordea la ciudad es creación romana. En efecto, la superposición de las principales acequias de riego histórico de Elche sobre los limes de la centuriatio romana de Ilici, prueba el origen romano de este regadío (GozÁlvez, 1974); no obstante, fue durante la etapa de dominio árabe cuando se implantó una minuciosa reglamentación del reparto del agua salobre del Vinalopó, usos y costumbres asumidos por los conquistadores cristianos a partir de 1265 (GoZÁLVEZ, 1977: 203).

La escasa disponibilidad de agua y la necesidad de optimizar este recurso, hizo que los huertos de palmeras se concentraran en torno a una superficie de unas pocas hectáreas en las proximidades de la ciudad — la extensión máxima de este palmeral se alcanzó probablemente a mediados del siglo XIX, con algo más de 200 hectáreas- A este palmeral «urbano» se le ha bautizado con el nombre de palmeral histórico, ya que ocupa la zona donde se desarrolló más tempranamente el cultivo de la palmera en Elche. En el resto del municipio predominaba hasta principios del siglo XX una agricultura de secano, aunque es bastante probable que existieran palmeras dispersas en determinados sectores del campo, sobre todo en las proximidades de las zonas húmedas del Hondo y de las Salinas de Santa Pola.

Según Gaspar Jaén (JAÉN, 1994: 56), las grandes plantaciones de palmeras en torno a la ciudad se completaron en el siglo XVIII, gracias al dinamismo de la economía agraria y al crecimiento demográfico que experimentó Elche en esta centuria, un crecimiento que, paradójicamente, también fue la causa de la desaparición de varios huertos transformados en barrios residenciales. A finales del siglo XIX se aceleró la destrucción del palmeral, con el propósito de liberar suelo donde construir edificios y naves industriales. Sin embargo, a diferencia de lo que ocurrió en los siglos anteriores, estas destrucciones, que alcanzaron su cenit en las primeras décadas del siglo XX, no fueron compensadas con nuevas plantaciones de huertos en el palmeral histórico, puesto que el cultivo de la palmera ya no era suficientemente rentable como para hacer frente a los usos y actividades urbanos. Por el contrario, la llegada de agua sobrante del Segura al campo de Elche a principios del siglo $\mathrm{XX}$, posibilitó que se plantaran nuevos huertos de palmeras en antiguas zonas de secano, 


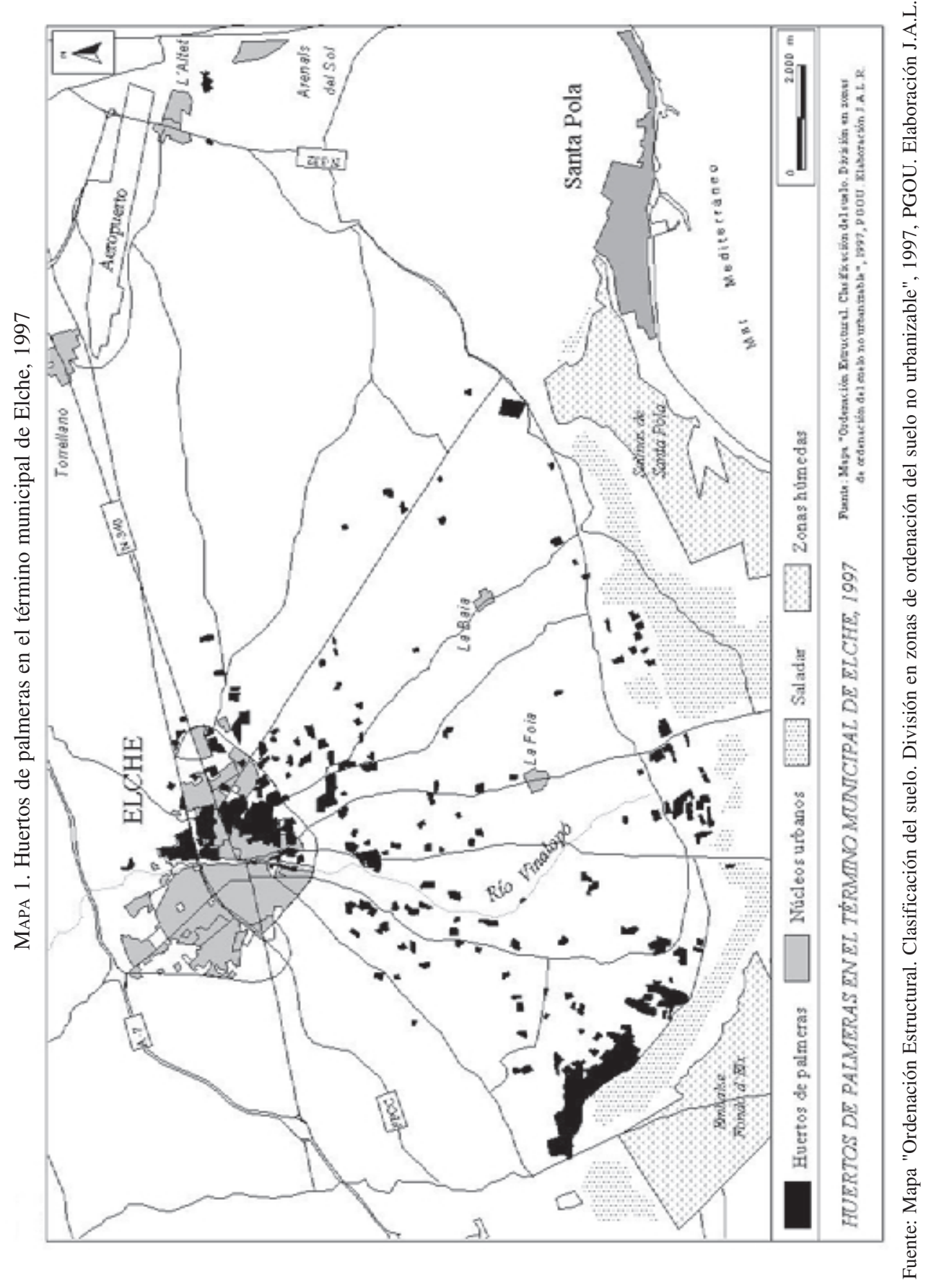


sobre todo en el cono aluvial del río Vinalopó y en las proximidades del Hondo (mapa 1), con una estructura y una organización similar a la que se venía practicando en el palmeral histórico de Elche.

Aunque en 1933 se dictan las primeras disposiciones para proteger el palmeral de Elche, las agresiones fueron continuas a partir de 1970, tanto en el palmeral histórico - ocupación urbana de los huertos de palmeras - como en el palmeral existente en el campo - arranques ilegales de palmeras, construcción de chalets dentro de huertos, etc.- . En la actualidad, el palmeral histórico, que coincide grosso modo con el territorio ocupado por la antigua partida rural de Horts i Molins, cuenta con un total de 74 huertos (86 en 1900), en los que hay plantadas unas 80.000 palmeras. En el palmeral del campo, por su parte, hay alrededor de 110.000 palmeras, en una superficie de cerca de 450 hectáreas, frente a las aproximadas 150 hectáreas que ocupa el palmeral histórico.

El objeto de nuestro estudio es el palmeral histórico de Elche, declarado Patrimonio de la Humanidad el 30 de noviembre del año 2000, junto con algunos huertos localizados fuera de la extensión continua de esta parte del palmeral, pero absorbidos igualmente por el crecimiento urbano. Ni que decir tiene que este conjunto de huertos «urbanos» no puede ser mantenido en términos de rentabilidad económica. Aunque en los últimos años se ha conseguido reproducir in vitro una variedad de palmera autóctona que garantiza dátiles uniformes, de calidad y con valor comercial, la estructura de los huertos tradicionales dificultaría y gravaría la recolección de los dátiles, ya que la disposición de las palmeras y el tamaño reducido de las parcelas haría muy difícil el empleo de maquinaria. Además, sería necesario plantar las palmeras dentro de la parcela, es decir fuera de alineación, lo que a la larga podría suponer la desaparición de la estructura tradicional. En cambio, este palmeral, por su situación dentro de la ciudad, tiene un enorme potencial turístico, sobre todo después de obtener la distinción de la Unesco como Patrimonio de la Humanidad. A pesar de las enormes posibilidades de aprovechamiento turístico de esta parte del palmeral de Elche, las últimas actuaciones realizadas en algunos huertos está poniendo de manifiesto que la gestión y la ordenación de los huertos de palmeras no es la más adecuada para mantenerlos y conservarlos en buen estado y con su impronta agrícola intacta.

\section{Aproximación al palmeral de Elche como patrimonio}

\subsection{La «patrimonialización» de un espacio agrícola singular}

La significación del concepto de patrimonio depende de criterios de valoración que, por su naturaleza eminentemente social, han sido y son cambiantes a lo largo de la historia de la humanidad. Probablemente, los primeros grupos humanos que formaron sociedades complejas ya contaban con ciertos elementos de la naturaleza o bien creados por ellos mismos, cuyo valor simbólico y reconocimiento social sobrepasaba el valor real que éstos tenían en función de sus características o de su utilidad. El concepto de patrimonio, por lo tanto, ha experimentado un largo proceso de elaboración, aunque el consenso social sobre lo que es y no es patrimonio comienza a fijarse en el Renacimiento, y se consolida en su acepción cultural más clásica en los siglos XVIII y XIX, coincidiendo con la vigencia de los presupuestos culturales de la ilustración y los movimientos burgueses. El patrimonio decimonónico lo constituían fundamentalmente los grandes monumentos, las obras y creaciones artísticas antiguas y contemporáneas, y los restos del pasado, muy valorados por movimientos artísticos de la época como el romanticismo.

Aunque se trataba de un patrimonio eminentemente cultural, a mediados del siglo XIX también se comienza a reconocer valor patrimonial a algunos elementos de la naturaleza. 
Los primeros atisbos de patrimonialización y conservación de la naturaleza se hacen, no obstante, desde valores estéticos y culturales, antes que desde valores biológicos o naturalistas (CRUZ, 2001: 312). En efecto, los espacios naturales más valorados en esos momentos eran aquellos que se acercaban al cliché paisajístico exaltado por el romanticismo, esto es, la monumentalidad, la belleza y lo pintoresco. Además, ese nuevo patrimonio era percibido más como un símbolo de identidad nacional-cultural que como una representación valiosa de un tipo de naturaleza o de ecosistema. No es de extrañar, por lo tanto, que las áreas de alta montaña, que sintetizan en sus paisajes los valores de patrimonialidad de esa época, fueran los primeros espacios naturales protegidos en el mundo. En España, por ejemplo, el primer Parque Nacional que se declaró fue la montaña de Covadonga, en 1918, por sus valores paisajísticos y por constituir un hito simbólico de la historia nacional, al situarse en este lugar el inicio de la reconquista cristiana.

El palmeral de Elche comienza a ser investido de valores patrimoniales a principios del siglo XX. La belleza de su paisaje, el exotismo inherente a un árbol como la palmera, más propio de otras latitudes, y su origen árabe, sobre el que frecuentemente fantasearon los viajeros ilustrados del siglo XVIII y del XIX, fueron motivos suficientes para que se diera un consenso social acerca de sus valores. No obstante, hubo de esperar a las grandes destrucciones que sufrió este espacio en los primeros años del siglo XX, para que la clase ilicitana de un mayor nivel cultural alzara la voz en defensa del palmeral, e hiciera de este lugar una de las señas de identidad de la ciudad. Desde ese momento, los huertos de palmeras de Elche fueron patrimonializados por la sociedad ilicitana, es decir, investidos de tres rasgos definitorios: durabilidad, valor y carácter comunitario (CRUZ, 2001: 310).

- Durabilidad, porque el palmeral de Elche es un legado del pasado que se ha de conservar y transmitir a las generaciones futuras, como así se reconoció en 1933 con la aprobación de un Decreto que declaraba de interés social su mantenimiento;

- Valor, porque existe el consenso de que los huertos de palmeras de Elche valen más que lo que son físicamente, y más de lo que generan desde el punto de vista económico como espacio productivo;

- Carácter comunitario, porque más allá de la propiedad jurídica de los huertos de palmeras, el palmeral es del conjunto de la sociedad, como así ha sido reconocido desde 1933, por el Decreto aprobado ese mismo año, por la Ley valenciana de Tutela y Protección del palmeral de 1986 y por la UNESCO, con su declaración de Patrimonio de la Humanidad en el año 2000.

El palmeral de Elche es un espacio agrícola creado por el hombre con fines productivos, pero su consideración como patrimonio a principios del siglo XX no se fundamentó en los valores histórico-culturales que tienen tanto la forma de organización del cultivo como las labores o tareas agrícolas propias de este agrosistema. El palmeral de Elche fue patrimonializado sobre todo por los valores que resaltaron, difundieron, y en ocasiones falsearon, los viajeros extranjeros que pasaron por Elche en los siglos XVIII y XIX, esto es, su exotismo y su paisaje pintoresco, que asemejaban al de los oasis del norte de África y del Medio Oriente. Es decir, la consideración del palmeral que trascendió a la sociedad fue la de un jardín exótico, ligeramente modelado por la mano del hombre. Esta noción del palmeral, que en cierta manera ha sobrevivido hasta fechas muy recientes, hizo que se valoraran más los elementos pseudonaturales —el árbol, el «bosque» de palmeras-, que los humanos - la organización del cultivo, las técnicas agrícolas-, como así se desprende del intento de declaración del palmeral de Elche como Parque Nacional en 1924. 


\section{Cuadro 1 \\ ORGANIZACIÓN DE LOS HUERTOS DE PALMERAS Y ELEMENTOS MÁS REPRESENTATIVOS}

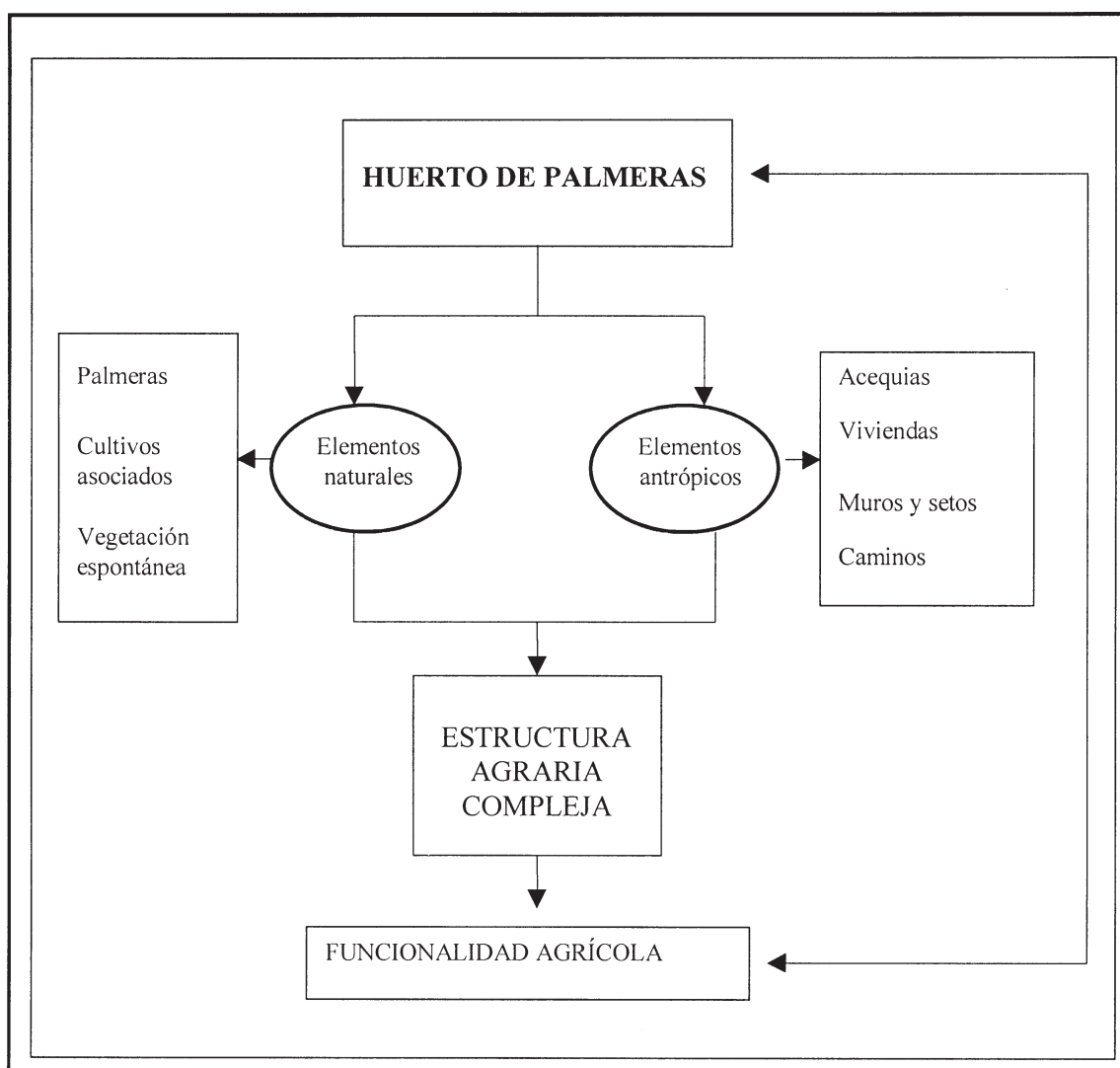

\section{Estructura:}

Los huertos están estructurados en parcelas o bancales, de forma casi siempre rectangular. En los límites de los bancales, sobre los márgenes, están plantadas las palmeras en filas sencillas o dobles, coincidiendo con el trazado de las acequias, sin duda uno de los elementos más valiosos desde el punto de vista patrimonial. Esa estructura está condicionada por el trazado de las acequias y por la búsqueda de la mayor rentabilidad de unos recursos escasos (al igual que el cultivo de oasis, la disposición de las palmeras busca liberar espacio para otros cultivos y crear espacios de sombra que mejoren su rendimiento).

\section{Elementos representativos:}

- La disposición de las palmeras en cuadrícula

- El sistema de riego

- Los cultivos asociados

- $\quad$ Las palmeras

Los elementos citados hasta ahora proporcionan identidad agrícola a los huertos de palmeras, independientemente de que estén en producción o no. Otros elementos importantes de este sistema y de su imagen agrícola tradicional son los muros que separan unos huertos de otros, el trazado de los caminos y la arquitectura de las viviendas de los agricultores, perfectamente integradas en el parcelario y en el paisaje del palmeral. 
En la década de 1980 y sobre todo de 1990, el concepto de Patrimonio comienza a ampliarse a elementos de la tradición popular, materiales e incluso inmateriales, como fiestas, conocimientos, usos, técnicas, utensilios, actividades, etc. De esta manera, muchos bienes rurales y espacios agrícolas tradicionales (también industriales), cotidianos hasta fechas recientes, han sido reconocidos como patrimonio, entre otras cuestiones ${ }^{1}$ por su enorme capacidad para documentar unas formas de vida humana y una cultura en proceso de desaparición. En este nuevo contexto, el palmeral de Elche ha aumentado su valor patrimonial, al vérsele reconocido su importancia como agrosistema singular, en el que destaca una organización del cultivo que es resultado de aportaciones técnicas y culturales que se remontan al periodo de ocupación romana (el sistema de acequias, por ejemplo), aunque su formación es fundamentalmente de origen árabe. La declaración del palmeral como Patrimonio Cultural de la Humanidad en el año 2000, sin duda, ha confirmado el enorme valor patrimonial de este espacio agrícola singular.

\subsection{El palmeral, Patrimonio de la Humanidad. Repercusiones en la función turística}

En 1972 la UNESCO (Organización de las Naciones Unidas para la Educación, la Ciencia y la Cultura) aprobó la Convención sobre la protección del patrimonio mundial cultural y natural. A través de este convenio, firmado hasta la fecha por 148 países, la UNESCO se propuso promover la identificación, la protección y la preservación del patrimonio cultural y natural en todo el mundo considerado especialmente valioso para la humanidad. Para conseguir ese objetivo se creó una lista, que sería completada cada año, de los bienes culturales y naturales (monumentos, grupos de edificios y sitios) que merecían tal reconocimiento, a propuesta de los estados miembros y tras la evaluación de un comité de expertos.

Sin embargo, en la definición de bienes culturales y naturales propuesta en la convención, no encajaban bien los espacios creados por la mano del hombre durante siglos con fines fundamentalmente económicos, que habían adquirido valores patrimoniales en fechas muy recientes. A principios de la década de 1990 la UNESCO decide identificar, proteger y preservar este «nuevo» patrimonio, llamado de forma genérica PAISAJE CULTURAL. Para conseguirlo se incentivó la inclusión de áreas rurales y espacios agrícolas singulares dentro de la lista —en la categoría de bienes culturales_-, se creó una nueva categoría de bienes mixtos -interacción hombre-medio- y se estableció el Premio Internacional Melina Mercouri, cuyo propósito es la salvaguarda y la gestión de los paisajes culturales.

Fruto de este reconocimiento, la Lista de Patrimonio Mundial de la UNESCO se ha visto ampliada en los últimos años con infinidad de paisajes culturales (también industriales), bien concebidos como jardines o parques en asociación con edificios, conjuntos religiosos y áreas cultivadas - Aranjuez (España, 2001), Lednice-Valtice (República Checa, 1996), Wachau (Austria, 2001), etc._- bien desarrollados por imperativo económico, en asociación con y en respuesta a un entorno natural - la región vitivinícola del Alto Duero (Portugal, 2001), el cultivo de arroz en las terrazas de las cordilleras filipinas (Filipinas, 2000), el palmeral de Elche (España, 2000), etc.- - Dentro de este último grupo de espacios agrícolas, el palmeral constituye un caso singular, ya que ha llegado hasta nuestros días sin apenas rentabilidad agrícola y a pesar de la presión urbana que ejerce sobre el mismo la ciudad de Elche (166.000 habitantes en un municipio de cerca de 200.000 habitantes en 1991).

1 Cruz Orozco apunta otros factores que concurren en el proceso de patrimonialización de muchos bienes rurales: las nuevas funciones que se asignan al medio rural en el contexto europeo y la radical transformación del marco político-administrativo español (CRUZ, 2001: 315-317). 


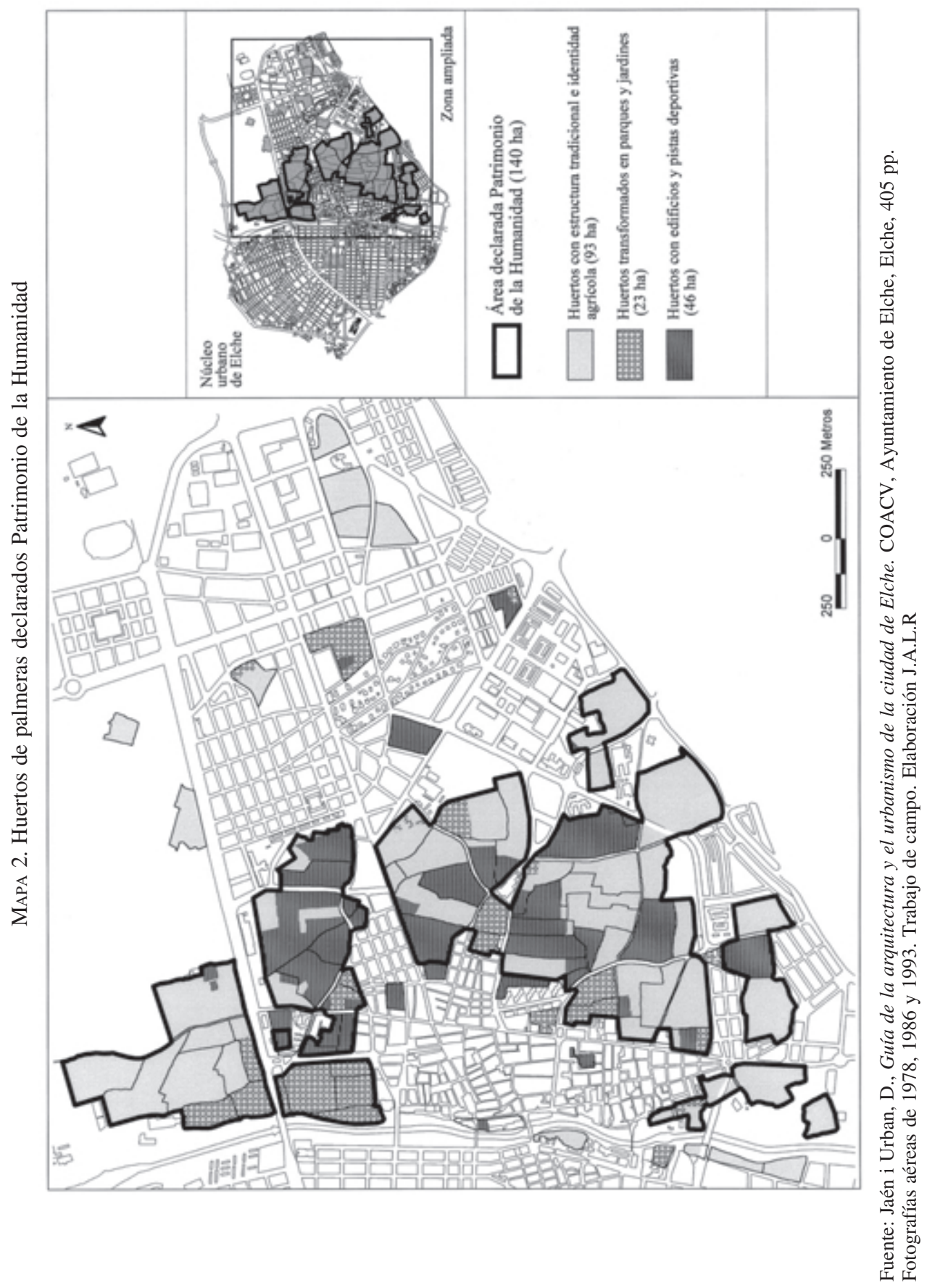


El palmeral de Elche es el primer espacio enteramente agrícola, o mejor dicho de origen agrícola, declarado Patrimonio de la Humanidad en España. El área declarada comprende los huertos incluidos en la antigua partida rural de Horts i Molins, hoy absolutamente integrada en la ciudad. Como se puede ver en el mapa 2, entre los huertos declarados Patrimonio de la Humanidad hay huertos con identidad agrícola (en producción o no) y huertos transformados y ocupados, tanto por edificaciones privadas como por infraestructuras y dotaciones públicas — parques y jardines-. Cabe pensar que la UNESCO aprobó la inclusión de estos huertos en el área declarada, por compartir un origen común y constituir una unidad espacial con el resto del palmeral agrícola de la partida Horts $i$ Molins, no tanto como reconocimiento a las políticas de «ordenación» del palmeral emprendidas por el Ayuntamiento de Elche desde 1950, que han sido las causantes de que muchos huertos de palmeras hayan sido parcialmente urbanizados y edificados. Prueba de ello es que los criterios en los que se basa la declaración del palmeral sólo hacen mención a los valores históricos y culturales del sistema agrícola, valores que han desaparecido por completo de algunos huertos incluidos en el área distinguida por la UNESCO.

Aunque la inclusión de un Bien en la Lista de Patrimonio Mundial tiene un alto valor simbólico y obliga a los Estados que lo representan a proponer medidas de gestión y protección, la trascendencia real de este reconocimiento suele ser escasa. La UNESCO no participa directamente en la gestión de los Bienes declarados ni proporciona recursos (humanos, técnicos o económicos) para el mantenimiento del Patrimonio de la Humanidad, salvo que esté en serio peligro de desaparición y los estados «propietarios» no puedan hacer frente a su recuperación. Tan sólo se compromete a promocionar el Patrimonio de la Humanidad, a través de publicaciones especializadas y de programas de enseñanza y educación, y a constituir un foro de cooperación internacional sobre la conservación del patrimonio cultural y natural. En realidad, lo que verdaderamente pretenden los grupos públicos y privados interesados en lograr esta distinción es aprovechar la difusión y el reconocimiento social que reciben los bienes declarados Patrimonio de la Humanidad para lograr con más facilidad subvenciones y ayudas económicas para su conservación y mantenimiento, y sentar las bases para lanzar, consolidar o recualificar, según los casos, la actividad turística.

Sin duda, el objetivo principal suele ser el desarrollo del turismo. Esto es especialmente palpable en los casos en los que el bien declarado no tiene un reconocimiento ni una popularidad manifiesta antes de integrar la lista de la UNESCO. En estos casos, la propia acción de declaración es la principal responsable de que se conviertan es lugares preferentes para la práctica turística. En ello tiene mucho que ver la publicidad gratuita que los medios de comunicación hacen de los bienes Patrimonio de la Humanidad, sobre todo inmediatamente después de la declaración, aunque la importancia creciente de esta distinción les garantiza una difusión más o menos permanente, a través de las revistas especializadas en viajes y de la propia labor divulgativa desarrollada por la UNESCO. Tampoco debemos de olvidar que la marca Patrimonio de la Humanidad, que se ha incorporado incluso a las denominaciones de origen turístico, se utiliza cada vez con más éxito en la promoción turística. La razón es clara, en un momento de valoración creciente del patrimonio cultural por parte de la demanda turística, la marca Patrimonio de la Humanidad da ciertas garantías de calidad y autenticidad respecto a los bienes declarados. Además, su significado es conocido por un número cada vez mayor de personas.

Publicidad gratuita y marca inciden directamente en la llegada de visitantes a los lugares Patrimonio de la Humanidad. En Elche, por ejemplo, el número de consultas a la Oficina de Turismo se triplicó en el primer puente después de la declaración del palmeral y aumentó un 55\% durante las fiestas de Semana Santa, cinco meses después del reconoci- 
miento de la UNESCO ${ }^{2}$. Sin embargo, ese aumento de visitantes puede verse reducido a un fenómeno pasajero, si la declaración no va acompañada de otras medidas que sirvan para crear un producto turístico de calidad, basado en el enorme atractivo diferencial que un Patrimonio de la Humanidad puede y debe conferir al destino donde se radica.

\section{La gestión del palmeral de Elche}

Durante los siglos en los que ha predominado una economía básicamente agraria, los huertos de palmeras han funcionado, gracias a su original concepción y organización, como unidades agrícolas familiares altamente productivas. Sin embargo, como ocurre con cualquier otro espacio económico sujeto a las leyes del mercado, los huertos de palmeras han dado paso a otros usos cuando el valor del suelo ocupado por el cultivo ha superado el valor del rendimiento económico generado por éste. Esto ha sucedido con cierta frecuencia desde el siglo XVIII en los huertos más próximos a la ciudad, debido a las necesidades de suelo donde construir viviendas y a las dificultades que planteaba la ocupación de otros terrenos, dado el emplazamiento de la ciudad antigua entre el río-rambla Vinalopó y los propios huertos de palmeras. No obstante, esta circunstancia no generó un rechazo en la población hasta principios del siglo XX.

En esas fechas se asiste a la patrimonialización del palmeral de Elche, y con ello a la formulación de propuestas para lograr su total conservación, al margen de su rentabilidad agrícola. La primera figura de protección del palmeral fue aprobada por el Ministerio de Agricultura de la Segunda República en 1933. Se trataba de un Decreto que prohibía la tala de palmeras vivas y todos aquellos actos que pudieran impedir su normal desarrollo en el término municipal de Elche (JAEN, 1989: 158). A su vez, el Decreto creaba la figura del Patronato, un órgano que debía de encargarse de la gestión del palmeral, que seguía bajo titularidad privada en su mayor parte. Por desgracia este Decreto, que estuvo vigente hasta 1986, tuvo una aplicación mínima —el Patronato no comenzó a funcionar hasta 1982 - y su espíritu conservacionista fue transgredido en innumerables ocasiones.

Después de la Guerra Civil y los años de posguerra, periodo en el cual se revitalizó la rentabilidad económica del palmeral debido a la falta de alimentos y a la escasez de materias primas, el suelo ocupado por los huertos, céntrico y barato, comenzó a ser muy apetecido por el capital, dado su enorme potencial de aprovechamiento urbanístico. Por este motivo, el Ayuntamiento de Elche, garante de los intereses privados de la época, se apoyó en un contexto de fuerte crecimiento demográfico y pérdida de rentabilidad de los huertos de palmeras, para facilitar, mediante la aprobación de dos documentos legales, la utilización urbana del palmeral, y atenuar así la firme prohibición del Decreto de 1933. Estos documentos son las «Ordenanzas adicionales a las generales de construcción para regular la edificación en zonas de palmerales», de 1951, y el «Plan Especial de Ordenación de los palmerales de Elche», aprobado en 1972 e incluido en el Plan General de Ordenación Urbana de 1973.

Este último Plan establecía una zonificación del palmeral de la ciudad —el palmeral histórico- en tres grandes grupos: palmerales públicos, palmerales de reserva y palmerales sociales. La zona de palmeral social integraba los huertos en los que se admitían usos no agrícolas, así que fue ocupada en los años sucesivos por viviendas, hoteles, pistas deportivas, parques, iglesias, etc. Esta ocupación urbana supuso la desaparición y/o alteración en los huertos afectados, de algunos elementos patrimoniales de enorme valor, como los cultivos asociados o el sistema de riego. Sin embargo, para el grueso de la opinión

2 Diario La Verdad, miércoles 18 de abril de 2001. 
pública la agresión al agrosistema como patrimonio no fue tan evidente, puesto que las edificaciones respetaban a primera vista las palmeras y la trama parcelaria ${ }^{3}$. Al margen de la ocupación urbana de los huertos «sociales», el Plan nunca representó una verdadera ordenación del palmeral. Una zonificación basada en criterios funcionales y espaciales hubiera concentrado los usos urbanos en una o a lo sumo en dos zonas determinadas del palmeral, con el fin de liberar el resto de la presión urbanística. Desgraciadamente no se hizo así, y en la actualidad el palmeral se encuentra gravemente fragmentado, haciendo imposible incluso el diseño de un circuito abierto que comunique los huertos de norte a sur.

El Decreto de 1933 y el Plan Especial de 1972 estuvieron vigentes hasta 1986. En esta fecha la Generalitat Valenciana aprobó la Ley de Tutela y Protección del Palmeral, que derogaba en su totalidad lo que hasta entonces se había legislado, y dio el visto bueno al nuevo Plan General de Ordenación Urbana del municipio, el primero redactado y aprobado en periodo democrático. Con el PGOU, los huertos de la ciudad privados y públicos sin edificar, fueron calificados como Sistemas Generales de Espacios Públicos, lo que a la larga obligaba al Ayuntamiento a lograr su adquisición. La Ley de Tutela y Protección del Palmeral, por su parte, diseñaba un nuevo modelo de protección jurídica encaminado a sistematizar las medidas de tutela del palmeral, hasta 1986 dispersas, y unificar la estructura del órgano que debía aplicarlas ${ }^{4}$, con el objetivo de atajar las agresiones al palmeral y mejorar su gestión. Aunque esta Ley de Tutela es un documento completo y bien desarrollado desde el punto de vista técnico (MEDINA, 1998: 126), contiene algunas lagunas en lo que se refiere a la protección de los elementos estructurales de los huertos de palmeras —no los protege explícitamente-. Además, ha faltado voluntad política para que su aplicación sea correcta. Baste recordar que el Patronato, que es el máximo órgano de gestión del palmeral propuesto por la Ley, sólo se reúne una vez al año, y además no dispone de fondos económicos para ayudar a los agricultores a mantener en buen estado los huertos de palmeras.

La falta de rentabilidad económica de los huertos de palmeras, junto a la inexistencia de ayudas para mantenerlos y las limitaciones de usos a los que estaban sujetos después de que el PGOU de 1986 los incluyera en el apartado de Sistemas Generales, dio como resultado el abandono generalizado de las explotaciones agrícolas privadas que todavía sobrevivían, más mal que bien, en la ciudad. Esta situación de abandono y decadencia se prolongó hasta 1996. En esta fecha el Ayuntamiento decide unilateralmente establecer una serie de líneas de actuación encaminadas a frenar el deterioro del palmeral y a fomentar su recuperación, dada la inoperancia del Patronato y de la Conselleria de Cultura, organismo que no ha acabado de asumir las competencias que le son propias por Ley.

Entre estas líneas de actuación destaca la creación de un sistema de ayudas para el mantenimiento de los huertos de palmeras —el «cheque verde»—, el impulso de una entidad pública especializada en investigaciones sobre el palmeral — la Estación Phoenix-,

3 La ocupación urbana y la consiguiente agresión al palmeral fue mucho más sutil que la que se dio a finales del siglo XIX y principios del XX. Sin embargo, en muchos casos la agresión en los años 1970 y 1980 iba más allá de las obras de construcción de un edificio o de una pista deportiva. Normalmente, en estos huertos transformados se suprimía el abono, y el riego tradicional era sustituido por otro compatible con los nuevos usos, aunque en ocasiones inadecuado para las palmeras. Con el tiempo, los árboles ornamentales introducidos en las parcelas han ido desplazando a las palmeras, que además han visto limitada su capacidad de reproducción a partir de los huesos de los dátiles, debido a la supresión del riego tradicional, a la alta frecuencia de las tareas de limpieza y a la impermeabilización de amplias superficies. Además, el precio de las palmeras de vivero es alto, lo que ha limitado la posibilidad de reponer los ejemplares que han ido desapareciendo. El resultado ha sido un empeoramiento del estado vegetativo de las palmeras, una reducción del número de palmeras por huerto y, en consecuencia, una pérdida significativa de la calidad paisajística del conjunto.

4 Exposición de Motivos de la Ley 1/1986. 


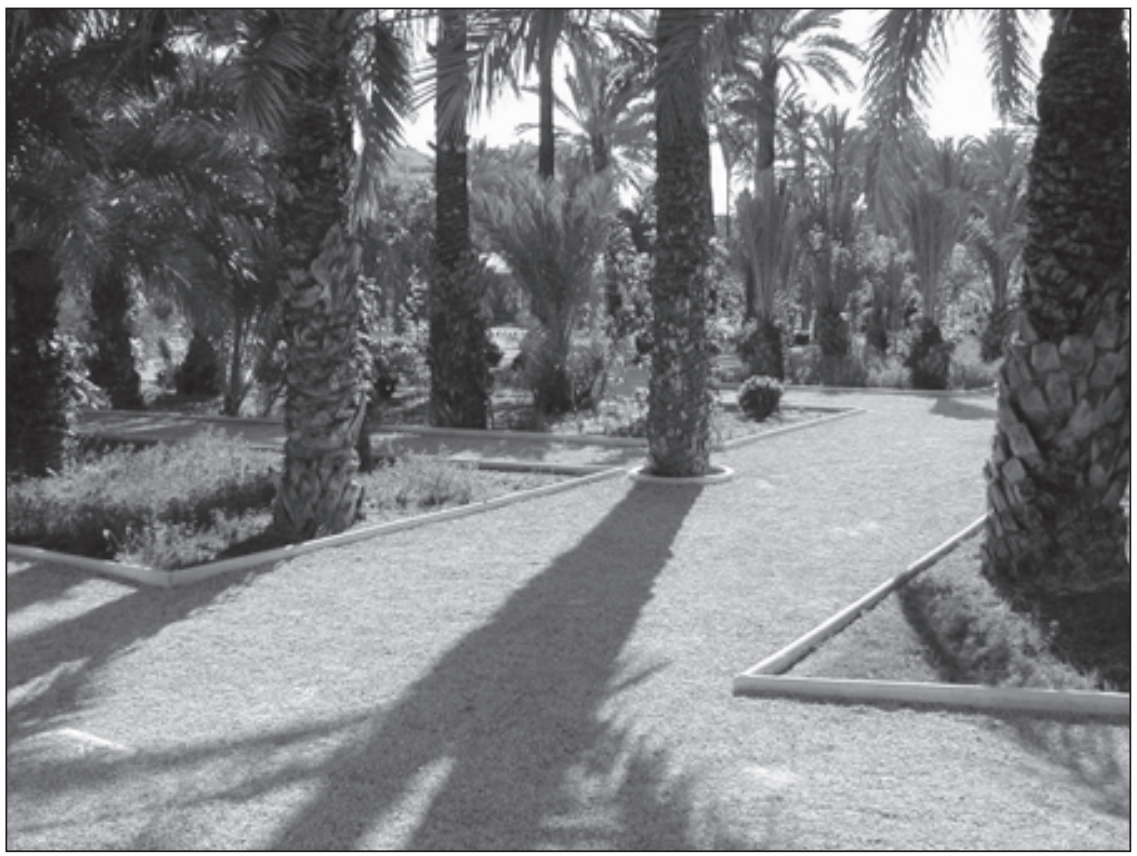

Fото 1. Huerto del Carmen (transformado en el Jardín Jaume I en el año 2000).

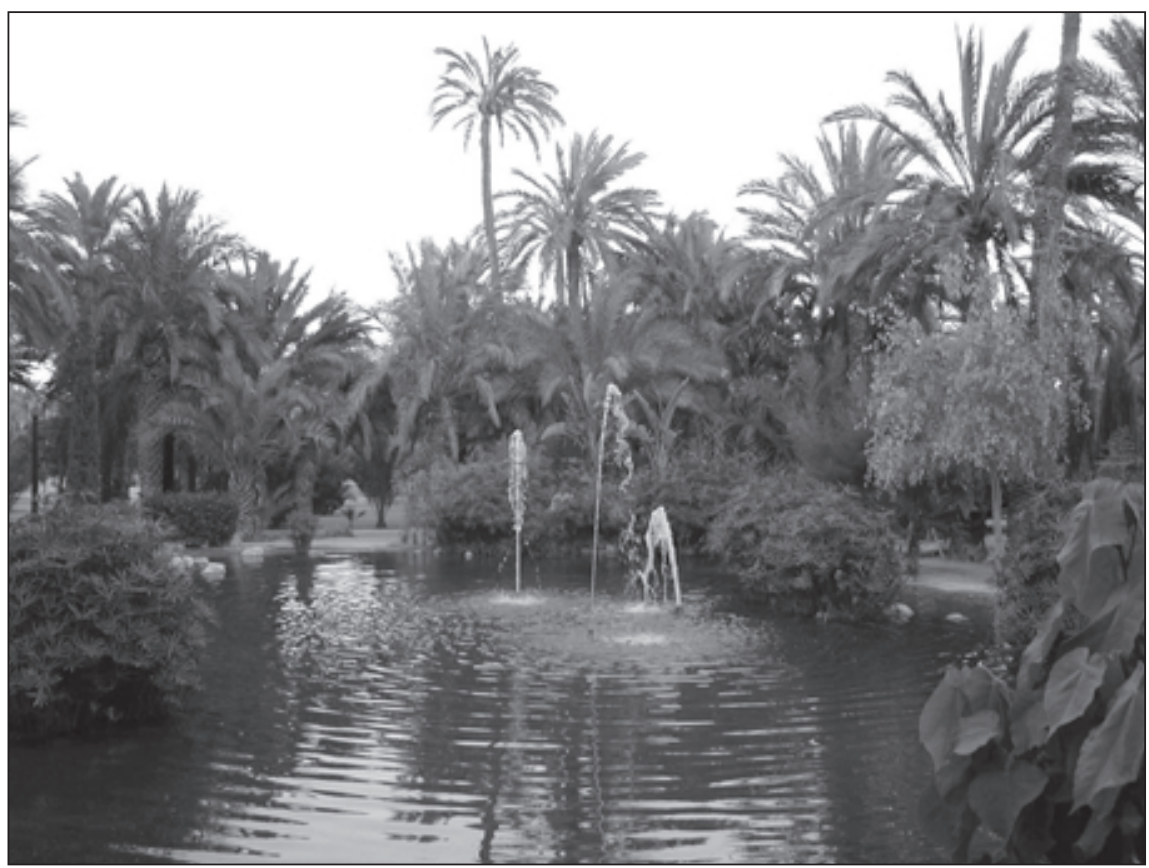

Fото 2. Huerto del Borreguet (transformado en el parque Filet de Fora en el año 1996). 


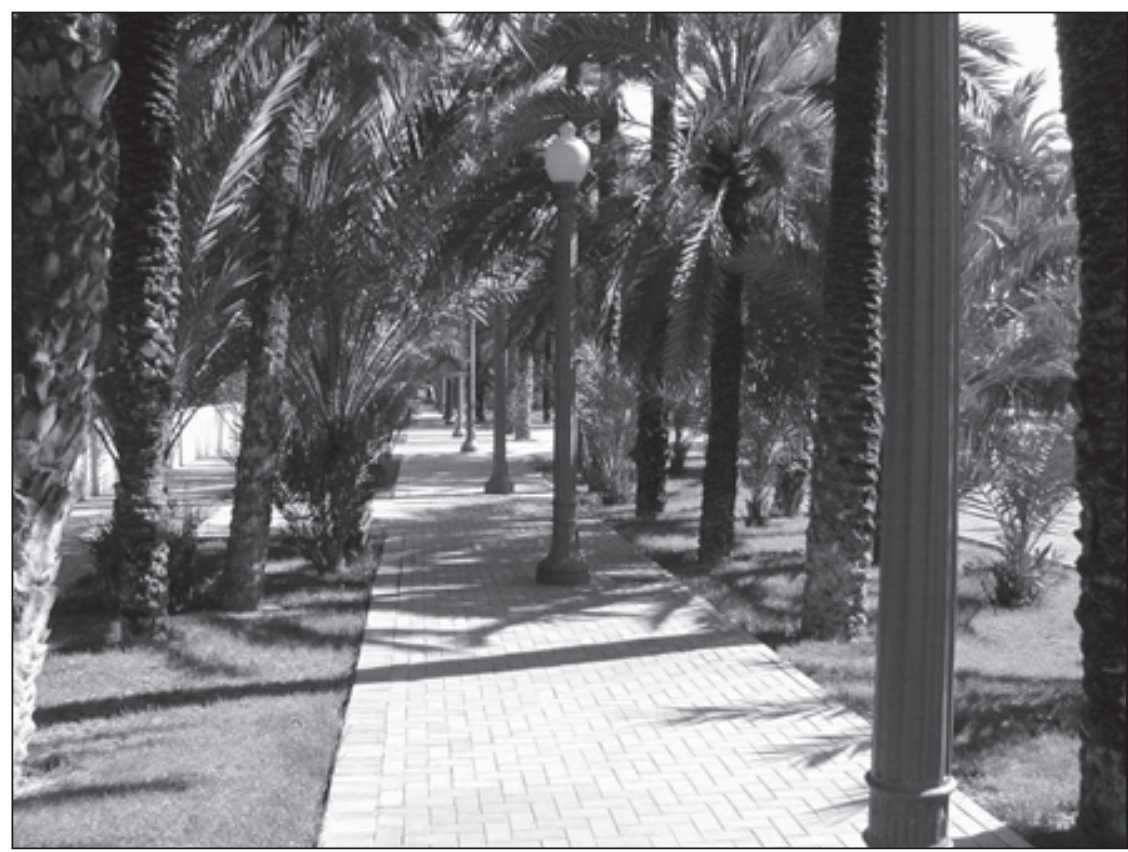

Fото 3. Huerto de Don Julio (transformado en el parque en 1996).

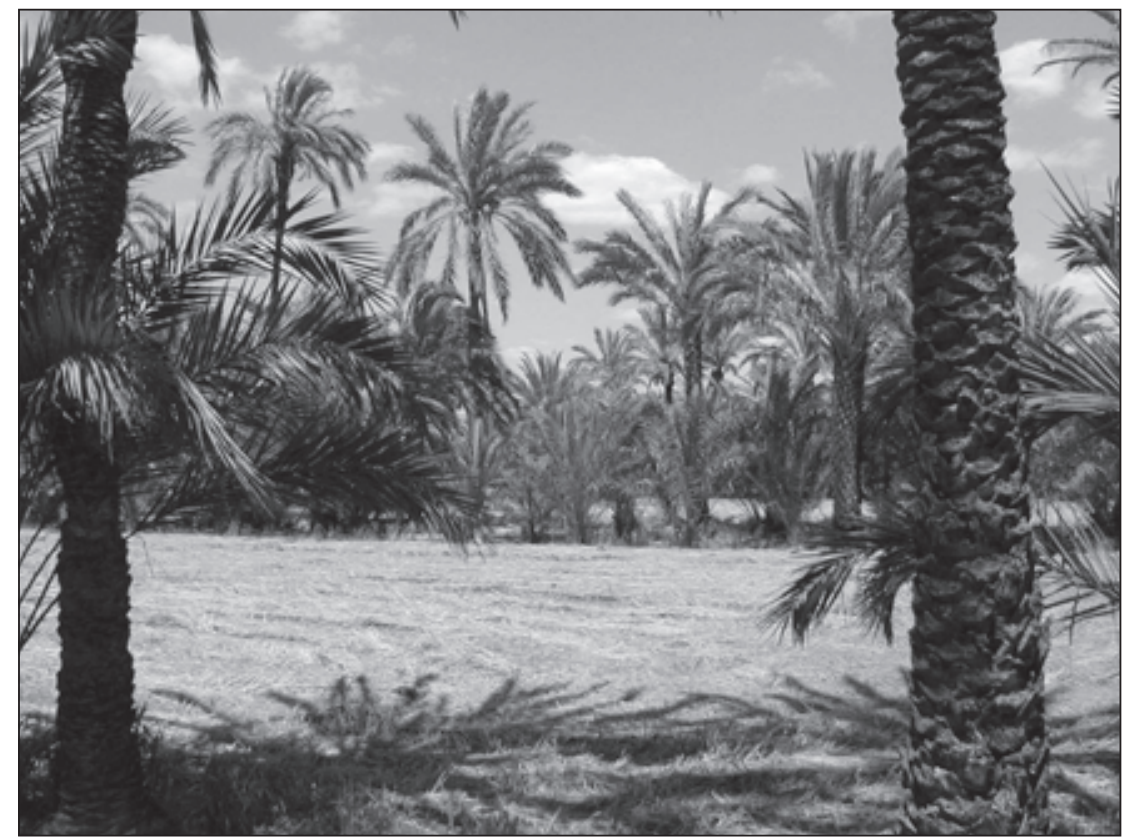

Fото 4. Huerto con identidad agrícola. 


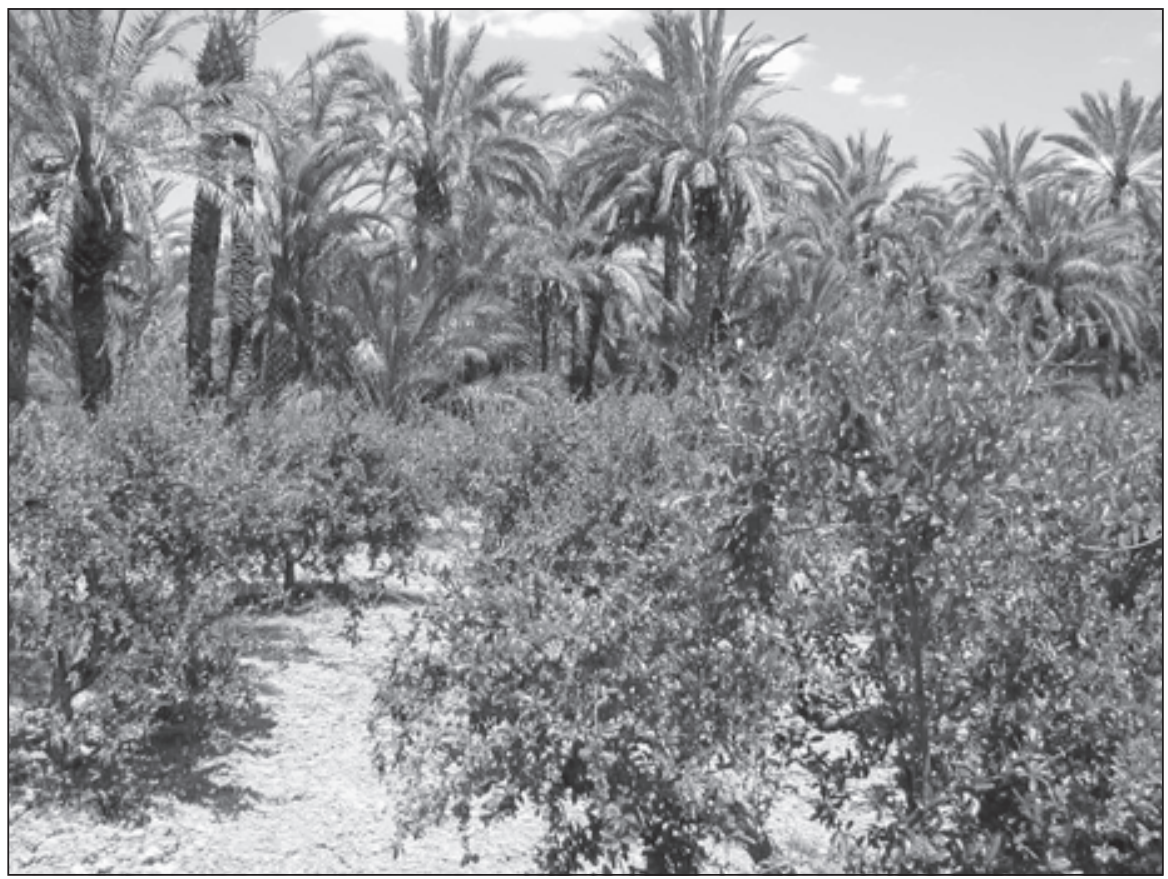

Fото 5. Huerto con identidad agrícola.

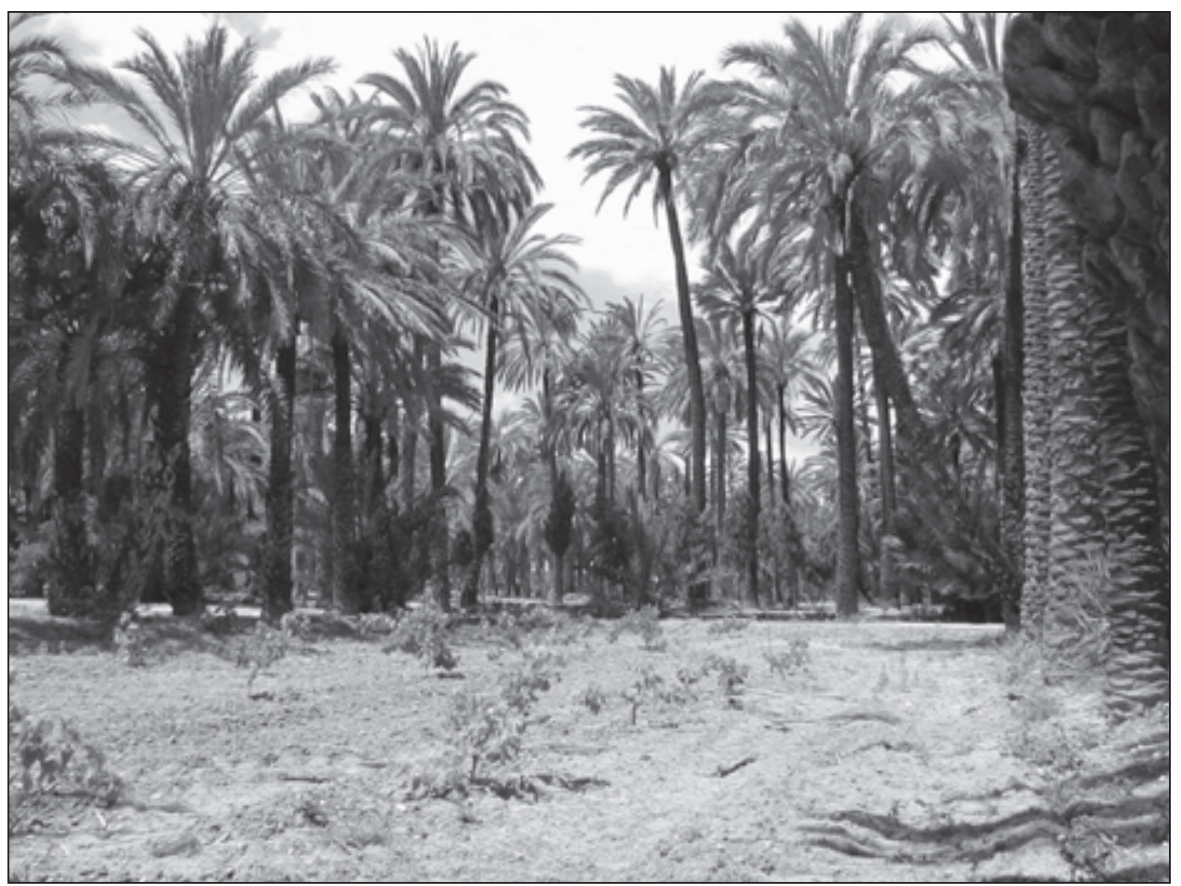

Fото 6. Huerto con identidad agrícola. 
la adquisición de los huertos de palmeras privados incluidos dentro de los Sistemas Generales, la actuación directa en los huertos privados en peor estado de conservación (a través de convenios o con carácter subsidiario a cargo de los propietarios) y la apertura al público de los huertos con identidad agrícola incluidos en los Sistemas Generales. Aunque el interés que ha mostrado el Ayuntamiento en mejorar la situación de un bien patrimonial que estaba perdiéndose lentamente es digno de elogio — hay que recordar que el palmeral, aunque patrimonio cultural, es un espacio agrícola necesitado de cuidados permanentes-, hoy podemos constatar que la protección del palmeral no ha sido ni es la más adecuada, ya que ciertas actuaciones de acondicionamiento y apertura de los huertos a la población han supuesto una transformación absoluta del espacio agrícola y la pérdida de elementos patrimoniales de gran valor.

Con la (buena) intención de dotar a la ciudad de nuevas zonas y espacios verdes, el Ayuntamiento, efectivamente, ha convertido huertos de palmeras en parques y jardines, de los que se ha borrado por completo la identidad agrícola del espacio originario. La cuestión es si sólo manteniendo las palmeras, la «fachada» del huerto, estamos contribuyendo a conservar el patrimonio cultural ${ }^{5}$. Pensamos que tal y como sucede con los monumentos y los edificios históricos, la adaptación de un espacio cultural concebido en un contexto histórico y funcional determinado, no debe en ningún caso suponer la pérdida de la identidad de ese espacio, es decir, de aquellos elementos a partir de los cuales podemos «reconstruir» la cultura y la actividad humana para la cual fue realizado. El hecho de que ni la Ley de Tutela del Palmeral ni el PGOU protejan explícitamente los huertos de palmeras como espacios agrícolas, con unas características y unos elementos representativos, debe obligar a las autoridades responsables a promover medidas que establezcan de una vez por todas la forma más adecuada de actuar en los huertos de palmeras, siempre desde el principio de la conservación del patrimonio. Afortunadamente, la declaración de Patrimonio de la Humanidad está haciendo comprender a la sociedad ilicitana que si la UNESCO ha valorado fundamentalmente las características histórico-culturales de los huertos de palmeras, no se debe intervenir en los mismos borrando o confundiendo esas características con elementos y actuaciones inadecuadas.

El último episodio en la gestión del palmeral es la reciente propuesta de la Generalitat Valenciana de declarar el palmeral de Elche como Parque Natural. Esta medida, probablemente más política que medioambiental, constituye desde el punto de vista científico un error de primera magnitud, con independencia de que pueda tener repercusiones positivas en la conservación del palmeral. El palmeral de Elche es un espacio agrícola, cuyos valores ecológicos no son mucho mayores que los que pueda tener un campo de naranjos o de olivos. Si bien la Ley de Espacios Naturales de la Comunidad Valenciana (1994) recoge la posibilidad de proteger espacios surgidos de actividades humanas, no es menos cierto que esta posibilidad está condicionada al valor, interés o singularidad de los elementos naturales que contenga el mismo — el embalse del Hondo de Elche-Crevillente puede ser un buen ejemplo-. El espíritu de la Ley en ningún caso contempla la declaración de espacios como el palmeral, que recordemos ha sido reconocido por la UNESCO como Patrimonio Cultural (no natural) de la Humanidad.

5 Amorós J. y Fructuoso J.J., «Palmeral urbano: ¿folclore o patrimonio?», Diario Información, domingo 9 de enero de 2000. 


\section{El palmeral de Elche y la actividad turística}

\subsection{El uso turístico del palmeral}

El atractivo paisajístico del palmeral de Elche y su originalidad en el contexto agrario europeo, ha hecho que este espacio se convierta en objeto de interés, estudio y visita desde el siglo XVIII hasta nuestros días. Personalidades y viajeros como Alexandre de Laborde, Gustavo Doré, Charles Davillier o los españoles Pascual Madoz y Antonio José Cavanilles, pasaron por Elche y dejaron la impronta de su visión del palmeral en textos y grabados entre 1757 y 1862. Salvo excepciones puntuales, la visión que se divulgó del palmeral en esta época fue la de un espacio exótico con reminiscencias orientales. Se trataba de una visión que anteponía el concepto de bosque al de huerto, la espontaneidad y el desorden a la estructura rígida de las alineaciones y la palmera ornamental o salvaje a la palmera como árbol productivo.

Por desgracia, esta percepción del palmeral hizo fortuna, y las primeras actuaciones realizadas en huertos de palmeras con el objetivo de facilitar su visita, incorporaron elementos ajenos a la función y a la identidad agrícola del huerto — fuentes, jardines, etc.- , con el propósito de acercarse a la idea estereotipada del palmeral exótico. Esta práctica se consolidó definitivamente en la década de 1950 en el Huerto del Cura y en los huertos de palmeras que integran el actual Parque Municipal. Con el tiempo, ambos espacios han sufrido una transformación radical de huertos a jardines turísticos, a espacios de consumo fácil para los visitantes y los turistas de los municipios litorales de la Costa Blanca. De alguna manera, había que ocultar la «vulgar» naturaleza agraria de los huertos de palmeras, demasiado sobria y real para que los turistas de la época pudieran digerirla.

El turismo, de hecho, ha sido una actividad que ha influido frecuentemente en la transformación de espacios culturales, sobre todo cuando la percepción ideal que los turistas tienen de un espacio no coincide con la imagen real del mismo. Baste recordar la «andalucización» a la que se vio expuesto el centro histórico de Benidorm en los años 1960, para acercar su imagen al estereotipo de pueblo español que tenían los turistas extranjeros, o la reciente arabización de muchos edificios de Granada y Córdoba, con la que se pretende crear un (falso) entorno urbano acorde con el estilo artístico de los dos grandes tótems culturales y turísticos de estas ciudades: La Alhambra de Granada y la Mezquita de Córdoba.

El ajardinamiento del Huerto del Cura y del Parque Municipal constituye, asimismo, una recreación (pastiche) de un paisaje y de una realidad que nunca han existido en Elche. Por el contrario, se ha dañado irreparablemente la identidad agrícola de los huertos afectados, quizás un precio demasiado alto para satisfacer una actividad, el turismo, que apenas ha contribuido a la economía de la ciudad. Efectivamente, el uso turístico del palmeral normalmente queda reducido a visitas de un solo día, en muchos casos organizadas por los touroperadores de Benidorm, que fueron los primeros en incorporar estos dos enclaves en la oferta de ocio del turismo de sol y playa de la capital turística de la Comunidad Valenciana. Además, nunca hubo una verdadera transferencia de los visitantes del palmeral a la ciudad, lo que hubiera podido servir para dinamizar la actividad comercial del centro urbano.

En cualquier caso, conviene recordar que el Huerto del Cura y el Parque Municipal son todavía hoy los lugares más emblemáticos del palmeral de Elche, por su capacidad de atracción de visitantes, por constituir dos grandes zonas de esparcimiento para la población - sobre todo el Parque Municipal- e incluso por contar con valores artísticos de cierto interés — jardinería, edificaciones, mobiliario, fuentes, etc.—. Es más, la transformación 
de estos huertos en jardines de uso público quizás los ha salvaguardado de otras agresiones mucho mayores, como las que afectaron en los años 1970 a la mayor parte de los huertos incluidos en la zona de «Palmerales Sociales». Aún así, considerar estos dos enclaves como modelo de lo que se tiene que hacer en los huertos de palmeras para «abrirlos» a la población, tal y como se ha hecho hasta ahora en muchos huertos de la ciudad, constituye desde nuestro punto de vista un ejercicio de enorme torpeza en la gestión del patrimonio cultural, aunque muy probablemente de alta rentabilidad política.

La situación de la actividad turística en la ciudad de Elche apenas ha cambiado en los últimos años, a pesar del aumento de visitantes a la ciudad. Hasta el momento, el número de turistas reales que se alojan en Elche motivados por la oferta turística de la ciudad en general y por el atractivo del palmeral en particular apenas ha crecido, a pesar de la reciente construcción de varios hoteles en la ciudad. Estos nuevos hoteles atienden fundamentalmente a un turista de negocios, vinculado a la actividad empresarial del calzado y a la presencia en la ciudad de varios centros universitarios.

Además, los visitantes que llegan a la ciudad atraídos por el palmeral siguen acudiendo básicamente al Huerto del Cura y al Parque Municipal, aunque el Ayuntamiento está intentando añadir a la escueta lista de huertos visitables y con cierto «potencial» turístico, los nuevos parques nacidos de la política municipal de apertura de huertos emprendida a partir de 1996. Un buen ejemplo lo constituye «El Parc de Palmeres del Filet de Fora» -Huertos del Borreguet y del Monjo-, un espacio que ha comenzado a incluirse en los folletos turísticos, aunque su diseño populista, al que es ajeno tanto la cultura tradicional como las nuevas vanguardias del urbanismo de espacios libres, ha puesto al descubierto la improvisación y la falta de criterio con la que se ha trabajado en ésta y en otras intervenciones recientes, amén de la escasa sensibilidad con un patrimonio único. Sólo la declaración del palmeral como Patrimonio de la Humanidad parece que está haciendo replantearse al Ayuntamiento el tipo de turismo que se quiere impulsar y, en relación con ello, el modo de actuar en los huertos de palmeras con identidad agrícola que todavía quedan dentro de la ciudad.

\subsection{Propuestas de actuación}

En la nueva era del turismo, las motivaciones de la demanda son más complejas y heterogéneas. En este marco de nuevas expectativas, los recursos culturales y patrimoniales tienen un interés creciente para la población en general y para la demanda turística en particular, como así se desprende del aumento del turismo europeo de ciudades y cultura -un 17\% entre 1989 y 1993, según el European Travel Monitor- y de las previsiones de la Organización Mundial del Turismo, que basa el crecimiento de esta actividad en los próximos 25 años en tres pilares: el contacto humano, la sostenibilidad natural y la BúSQUeda de la AUTENTICIDAd CUlTURAL (MARChena, 1999: 15). Desde este punto de vista, los paisajes rurales y los sistemas agrícolas tradicionales, además de nuevo patrimonio cultural, se han convertido en verdaderos recursos turísticos $\mathrm{y}$, por lo tanto, en bienes productivos dentro de la actividad turística. En este contexto, aprovechar los escasos huertos de palmeras con identidad agrícola que todavía quedan en la ciudad de Elche para transformarlos en parques urbanos con bancos y farolas, constituye una agresión de primer orden al patrimonio cultural, pero también la pérdida de un recurso económico insustituible y de un elemento de enorme atractivo diferencial en el mercado turístico.

Como es sabido, una actividad turística bien planificada y desarrollada puede actuar como elemento inductor de la recuperación y la conservación del patrimonio cultural con «valor turístico», como ocurre con el palmeral de Elche. El reto, por lo tanto, es aprovechar 
el turismo para implementar las medidas adecuadas a través de las cuales mantener el palmeral histórico con su impronta agrícola y su autenticidad cultural intacta. Ciertamente es una tarea compleja, ya que se trata de un sistema agrícola situado dentro de una ciudad de tamaño medio-grande y que además no puede ser mantenido en términos de rentabilidad agrícola. No obstante, podemos apuntar algunos criterios de actuación que, desde nuestro punto de vista, deberían ser tenidos en cuenta:

- Fomentar la recuperación y la reutilización del patrimonio arquitectónico de los huertos de palmeras - las viviendas tradicionales - para localizar infraestructuras o servicios de bajo impacto ambiental (restaurantes, exposiciones, comercios, etc.). Con la destrucción de las casas de campo - las últimas derribadas son las situadas en los Huertos de Pastoret y de Felip, en marzo de 2002- de los huertos Patrimonio de la Humanidad, se pierde un elemento propio de este sistema agrícola y de su imagen y, por ende, un elemento patrimonial de gran interés y un potencial recurso turístico. Derribar edificios históricos, aunque de arquitectura popular, para volver a construir otros nuevos es un «lujo» demasiado grande para una ciudad que prácticamente carece de paisaje urbano tradicional.

- Situar las grandes infraestructuras turísticas que se prevean construir, en los huertos privados que ya han sufrido un alto grado de transformación (nunca en los huertos con identidad agrícola), así como en las parcelas vacías contiguas a los huertos de palmeras, siempre y cuando estas infraestructuras no obstaculicen la visión que sobre los huertos se tiene desde la ciudad. Conviene evitar el encerramiento que sufre el palmeral en algunos sectores de la ciudad, por la sustitución de las casas tradicionales, de dos o a lo sumo tres plantas, por edificios de gran altura. Esta situación es bien visible en la calle Filet de Fora, antiguo límite de la centuria romana, donde los edificios modernos han formado una auténtica muralla que impide la visión de los huertos adyacentes.

- Preservar los huertos con identidad agrícola para proyectos singulares que puedan integrarse en el espacio agrícola, sin dañar su imagen ni sus elementos característicos. El desarrollo de la actividad turística debe estar condicionada por el mantenimiento y el fomento del patrimonio sin impactos nocivos ni banalización del uso público de dicho patrimonio (MARCHENA, 1999: 19). La estructura de los huertos en parcelas permite infinidad de actuaciones respetuosas con el agrosistema. El respeto y la simbiosis con el entorno que se respira en las intervenciones artísticas de Eduardo Chillida en el caserío y en el medio rural de Zabalaga (Guipúzcoa), de Agustín Ibarrola en el bosque de Oma (Vizcaya), o de César Manrique en la isla de Lanzarote, son sólo algunos ejemplos de la puesta en valor del medio rural y natural a través del arte — como espacios expositivos de arte-.

- Evitar la museificación y el exceso de explotación turística del palmeral histórico de Elche. La función del patrimonio cultural va mucho más allá que la de servir de atractivo turístico. Es absolutamente necesario reservar huertos con identidad agrícola para desarrollar otros usos y actividades: educación ambiental-cultural, actividades recreativas, sociales — un buen ejemplo lo constituyen los «jardines urbanos» de muchas ciudades europeas, espacios agrícolas imbricados en la trama urbana que hoy destacan por su enorme valor social-, etc. Y hacer posible que aquellos huertos donde todavía viven agricultores puedan seguir siendo ocupados y trabajados como hasta ahora.

- Lograr una gestión turística del palmeral basada en estrategias cualitativas, que partan de la conservación y del cuidado de los huertos de palmeras como premisa 
primera y fundamental. Si este es un aspecto clave en el mantenimiento de los recursos culturales convencionales, más importante todavía es en un bien vivo como el palmeral, cuyas condiciones naturales (y estéticas, no lo olvidemos) dependen directamente del cuidado que reciben las palmeras, del riego, del abono, de la poda, etc. Con demasiada frecuencia la ordenación y la gestión de los espacios y los recursos turísticos son débiles, y los organismos públicos y privados priman más la preocupación por la promoción que por la gestión sostenible (TROITIÑo, 2000: 119).

- Fomentar una imagen turística del palmeral (y de la ciudad) acorde con la imagen representativa y originaria del bien declarado Patrimonio de la Humanidad. Utilizar exclusivamente imágenes que ensalzan la impostura del palmeral-jardín en la promoción de la ciudad, no ayuda a crear y consolidar una buena imagen turística de marca, que debe intentar basarse en lo singular. Además, el abuso de la utilización de la imagen del palmeral como un conjunto de parques con bancos, farolas y palmeras, crea cierta confusión entre los visitantes, que realmente no saben lo que van a encontrar cuando llegan a la ciudad.

Elche apuesta al comienzo del siglo XXI por un turismo urbano de calidad apoyado en el indiscutible valor patrimonial del palmeral y arropado por otros atractivos culturales - museos, yacimientos arqueológicos y sobre todo El Misteri d’Elx, Obra Maestra del Patrimonio Oral e Inmaterial de la Humanidad, una nueva categoría creada por la UNES$\mathrm{CO}$ - y otros elementos secundarios que se han reforzado en los últimos años — hoteles, imagen urbana, comercio, etc.- - El hecho de que el mayor atractivo turístico de la ciudad, el elemento a partir del cual se puede construir y definir el producto turístico de Elche, sea un espacio de origen e identidad agrícola, no debe en ningún caso representar una carga, al contrario, debe ser visto como una potencialidad, como una enorme ventaja respecto a otros destinos urbanos. Ciudades como Barcelona, Madrid, Sevilla, Valencia o Granada tienen parques y jardines botánicos igual o más famosos que el Huerto del Cura o el Parque Municipal. Sin embargo, ninguna de estas ciudades puede presumir de contar en el corazón de la ciudad, con un espacio agrícola con la calidad estética (fotos 4,5 y 6), el valor patrimonial y la historia de los huertos de palmeras de Elche.

\section{Bibliografía}

CRUZ OROZCO, Jorge (2001): «La revalorización de los recursos naturales y patrimoniales en el medio rural valenciano», en Martínez Puche, A. (Coord.) El desarrollo rural/local integrado y el papel de los poderes locales, Universidad de Alicante, FEVES, Alicante, pp. 309-331.

GOZÁLVEZ PÉREZ, Vicente (1974): «La centuriatio de Ilici», en: López Gómez, A. y Roselló Verger, V. (dirs) Estudios sobre centuriaciones romanas en España, pp. 101-113, Universidad Autónoma de Madrid, Madrid.

GOZÁLVEZ PÉREZ, Vicente (1977): El Bajo Vinalopó. Geografía agraria, Universidad de Valencia, Departamento de Geografía, Valencia, 270 pp.+ 8 láms. f.t.

JAÉN I URBAN, Gaspar (1989): Guía de la arquitectura y el urbanismo de la ciudad de Elche, COACV, Generalitat Valenciana, Ayuntamiento de Elche, Elche, 405 pp.

JAÉN I URBAN, Gaspar (1994): Les palmeres del migjorn valencià, Consell Valencià de Cultura, Generalitat Valenciana, València, $68 \mathrm{pp}$.

MARCHENA GÓMEZ, Manuel J. (2000): «Patrimonio y Ciudad: nuevos escenarios de promoción y gestión del turismo urbano europeo», en: Actas Turismo y Ciudad, IV Coloquio de Geografía Urbana y VI Coloquio de Geografía de Turismo, Ocio y Recreación, Asociación de Geógrafos Españoles, Ayuntamiento de Las Palmas, Las Palmas, pp. 15-28. 
MEDINA CORRECHER, Eduardo (1998): El Palmeral de Elche. Tutela jurídica y perspectiva urbanística como zona verde y espacio protegido en el planeamiento municipal, Instituto de Cultura «Juan Gil-Albert», Diputación de Alicante, Alicante, 236 pp.

PICÓ MELÉNDEZ, Francisco (1997): El Palmeral Histórico de Elche, Ajuntament d’Elx, Elche, $187 \mathrm{pp}$.

SEVILLA JIMÉNEZ, Martín (1985): Crecimiento y urbanización. Elche 1960-1980, Universidad de Alicante, Ayuntamiento de Elche, Valencia, 418 pp.

TROITIÑO VINUESA, Miguel Ángel (2000): «El turismo cultural en las ciudades españolas Patrimonio de la Humanidad», en Turismo cultural: el patrimonio histórico como fuente de riqueza, Fundación del patrimonio histórico de Castilla y León, Valladolid, pp. 111-135. 